\title{
Realistic human muscle pressure for driving a mechanical lung
}

\author{
Emeline Fresnel ${ }^{1,2^{*}}$, Jean-François Muir ${ }^{3}$ and Christophe Letellier ${ }^{1,2}$
}

\author{
${ }^{*}$ Correspondence: \\ emeline.fresnel@coria.fr \\ ${ }^{1}$ CORIA-UMR 6614 Normandie \\ Université, CNRS-Université et INSA \\ de Rouen, Campus Universitaire du \\ Madrillet, F-76800 Saint-Etienne du \\ Rouvray, France \\ ${ }^{2}$ ADIR Association, Hôpital de \\ Bois-Guillaume, F-76031 Rouen, \\ France \\ Full list of author information is \\ available at the end of the article
}

\begin{abstract}
Background: An important issue in noninvasive mechanical ventilation consists in understanding the origins of patient-ventilator asynchrony for reducing their incidence by adjusting ventilator settings to the intrinsic ventilatory dynamics of each patient. One of the possible ways for doing this is to evaluate the performances of the domiciliary mechanical ventilators using a test bench. Such a procedure requires to model the evolution of the pressure imposed by respiratory muscles, but for which there is no standard recommendations.
\end{abstract}

Methods: In this paper we propose a mathematical model for simulating the muscular pressure developed by the inspiratory muscles and corresponding to different patient ventilatory dynamics to drive the ASL 5000 mechanical lung. Our model is based on the charge and discharge of a capacitor through a resistor, simulating contraction and relaxation phases of the inspiratory muscles.

Results: Our resulting equations were used to produce 420 time series of the muscle pressure with various contraction velocities, amplitudes and shapes, in order to represent the inter-patient variability clinically observed. All these dynamics depend on two parameters, the ventilatory frequency and the mouth occlusion pressure.

Conclusion: Based on the equation of the respiratory movement and its electrical analogy, the respiratory muscle pressure was simulated with more consistency in regards of physiological evidences than those provided by the ASL 5000 software. The great variability in the so-produced inspiratory efforts can cover most of realistic patho-physiological conditions.

Keywords: Respiratory muscle pressure; Mechanical lung; Mechanical ventilation

\section{Background}

\section{Issues in noninvasive mechanical ventilation}

The main goal of mechanical ventilation is to assist the spontaneous breathing of a patient with acute or chronic respiratory failure. The ventilator improves the blood oxygenation and unloads the respiratory muscles by supplying a suitable level of pressure support [1]. Typically, a ventilator delivers a high pressure (often named "Inspiratory Positive Airway Pressure") during the inspiration and a low pressure (named "Expiratory Positive Airway Pressure") during the expiration. Noninvasive mechanical ventilation is thus quite tricky since the pressure cycle delivered by the ventilator must be synchronized with the patient breathing cycle, that is, the pressure rise to reach the upper pressure level must be triggered at the onset of the patient inspiratory effort and the

(c) 2014 Fresnel et al.; licensee Springer on behalf of EPJ. This is an Open Access article distributed under the terms of the Creative Commons Attribution License (http://creativecommons.org/licenses/by/2.0), which permits unrestricted use, distribution, and reproduction in any medium, provided the original work is properly credited. 
pressure release must be triggered when the patient ends his inspiration for breathing out. Such a good synchronization between the patient breathing cycle and the pressurization cycle delivered by the ventilator is important to ensure a better comfort and to reduce the patient work of breathing, although these points have not yet been clearly validated [2]. Patient-ventilator asynchrony is defined as a phase shift between the patient ventilatory cycle and the pressurization cycle delivered by the ventilator. There are various types of asynchrony events $[3,4]$ which can be detected using noninvasive measurements [5]: reducing their incidence allows to decrease the duration for which a patient needs mechanical ventilatory assistance [3]. The quality of the synchronization between the patient ventilatory cycle and the pressurization cycle delivered by the ventilator depends on patient physiological characteristics and on ventilator settings. Some parameters are considered as being critical for synchronizing the ventilator pressure cycle to the patient breathing dynamics: the sensitivity of the high pressure trigger [3], the low pressure value [6], the level of pressure support (the difference between the high and low pressure values) $[7,8]$ or the time during which the high pressure is delivered [9]. However, the way according which the pressure cycle is governed by patient inspiratory demand depends on the considered ventilators. Moreover, the terminology as well as the units of the settings present strong heterogeneities among the available ventilators [10].

Nowadays, bench test studies appear as the most appropriate and most effective way to compare performances of ventilators. Unfortunately, these studies reveal that there is a serious need for defining standardized protocols in order to obtain reliable and reproducible results [11]. We choose to focus on the problem of simulating the inspiratory effort delivered by the patient, that is, the dynamics of the breathing patterns as it can be produced with the active mechanical lung ASL 5000 (IngMar Medical, Pittsburgh, USA), one of the most flexible active mechanical lungs available in the market. The choice for this device results from the fact that it becomes very often used for testing performances of domiciliary ventilators [12-17]. It consists of a piston chamber driven by a software and whose dynamics can be adjusted by realistic parameters such as the resistance of the airways and the lung compliance. With such a device, it is quite easy to simulate the inter-patient variability clinically observed since the muscular pressure responsible for the inspiratory effort can be parametrized using predefined waveforms or designed by the operator (in the latter case, the curve is downloaded to the device). There is no consensus for designing the inspiratory effort [11] and all parameter values required to reproduce muscular pressure are very rarely fully reported, with the exception of Chatburn's studies [18]. Most often a semi-sinusoidal muscle pressure - as predefined in the ASL $5000-$ is used (Figure 1), but this was never compared to the (rare) physiological data available. This is mainly due to the fact that measuring a muscular pressure is not a trivial task and necessarily requires invasive measurements. Indeed, in common studies only the airflow and the pressure within the ventilatory circuit (as measured by the ventilator) are available. Airflow thus results from the interactions between the patient and his ventilator; it corresponds to the output of the system, the muscle pressure being the source signal. The ASL 5000 was thus designed for producing the airflow from a preset muscular pressure. In order to conduct a parametric study for investigating the quality of the synchronization between patient breathing cycles and the pressure cycles delivered by the ventilator, it is therefore convenient to produce muscular pressure time series depending on a few 


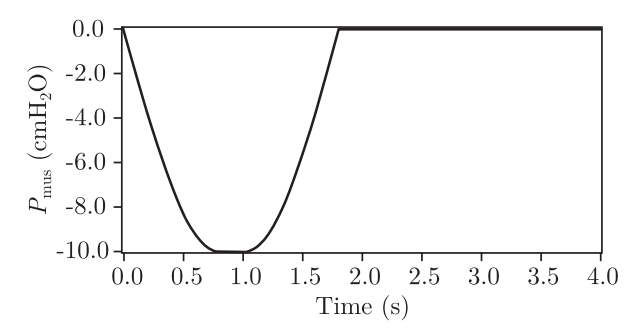

Figure 1 Muscle pressure curve. Respiratory muscular pressure used to drive the ASL 5000 mechanical lung. Sinusoidal half-wave model as proposed by the ASL 5000 software. Parameter values: Increase $=20 \%$, Hold $=$ $5 \%$, Release $=20 \%, T_{\text {tot }}=4 \mathrm{~s}, \mathrm{Amp}=10 \mathrm{cmH}_{2} \mathrm{O}$. Increase, hold and release are expressed as a fraction of $T_{\text {tot }}$.

parameters varied (with an increment as small as possible). Each parameter setting can thus be investigated for hundreds of patient ventilatory dynamics, that is, as it was tested on a cohort of hundreds of patients. In practice, the latter is nearly impossible to conduct because it is not possible to measure muscular pressure in a huge cohort of patients with the expected parameters, that is, according to our objective, varying the ventilatory frequency and the occlusion pressure within the target intervals. It is therefore convenient to simulate the corresponding muscular pressure time series for driving a mechanical lung as the ASL 5000: ventilators are thus tested as if they were connected to a large number of different patients. Such a procedure allows to make the study reproducible by any group having an ASL 5000 (something which is impossible to achieve with a database of measurements in patients).

Our objective is therefore to construct time series of the respiratory muscle pressure in agreement with physiological evidences for investigating ventilator performances under quite realistic conditions. For that purpose, we started from the equation of motion for the respiratory system, used to determine the muscle pressure $P_{\text {mus }}$. Based on an electrical analogy, the resulting mathematical model is then presented and some examples of inspiratory efforts are discussed.

\section{Mechanics of the respiratory system: historical aspects}

In the early 20th century, Armand Imbert investigated the relative velocities of spontaneous and triggered muscle contractions [19]. Using an electrical excitation produced by the discharge of a capacitor connected to a power source, contractions of the explored muscle were recorded through a drum maintained with a bandage. Muscle contraction can be divided into two phases (Figure 2): a relatively stiff contraction followed by a relaxation phase. Consequently, there is an obvious asymmetry between the contraction and the relaxation phases. The rate of contraction increases as the contraction becomes stronger. Similar results were found with spontaneous muscle contractions [19]. Regarding to the respiratory muscles, stronger contractions allow to increase the volume of the thoracic cage, thus inducing a larger negative pressure and then producing a stronger inspiratory flow.

\section{Equation of motion for the respiratory system}

The respiratory mechanics is mainly governed by the equation expressing the muscle pressure required for producing the airflow $Q_{\nu}$. There are three contributions to this 


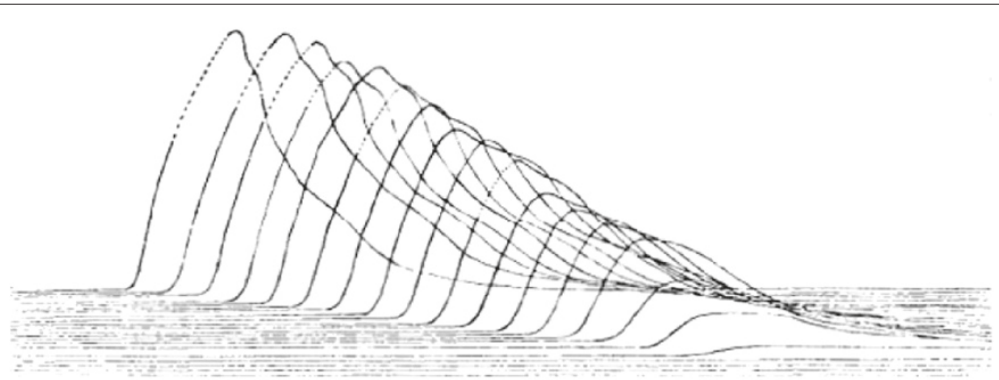

Figure 2 Imbert's muscle contractions. Triggered by capacitor discharges, muscle contractions are represented from bottom to top with an increasing intensity (from Imbert, 1911).

equation. First, the static property of the respiratory system implies that the energy per unit volume (physically equivalent to a pressure), $P_{\mathrm{el}}$, used to deform the respiratory system (lungs and thoracic cage) is proportional to the inspired volume $V$ and to the elastance $E$ of the respiratory system, that is,

$$
P_{\mathrm{el}}(t)=E V(t)
$$

Due to the relative precision of the data measured in patients, the elastance may be here considered as constant, at least during inspiration and expiration. In fact, the difference of elastance between inspiration and expiration will be implicitely taken into account in the different time constant $\tau_{c}$ and $\tau_{r}$ considered for modelling the muscle pressure as explained in the subsequent part of this paper. Second, the volume energy $P_{\text {res }}$ dissipated by the resistance $R$ of the respiratory system to airflow is given by

$$
P_{\text {res }}(t)=R Q_{v}=R \frac{\mathrm{d} V(t)}{\mathrm{d} t} .
$$

This component results from the air viscosity, that is, the loss of energy only due to interactions between the air and the airway walls: this term corresponds to the so-called Hagen-Poiseuille law. Third, the volume energy $P_{\text {in }}$ required to inflate the lung depends on the inertance $I$ of the respiratory system according to

$$
P_{\text {in }}(t)=I \frac{\mathrm{d} Q_{\nu}(t)}{\mathrm{d} t}=I \frac{\mathrm{d}^{2} V(t)}{\mathrm{d} t^{2}} .
$$

Elastance $E$ characterizes the static property of the lung mechanics and, resistance $R$ and inertance $I$ correspond to the dynamical properties of the respiratory system. The total pressure required to move the lungs is thus expressed as

$$
P_{\text {tot }}(t)=P_{\text {el }}(t)+P_{\text {res }}(t)+P_{\text {in }}(t)=E V(t)+R \frac{\mathrm{d} V(t)}{\mathrm{d} t}+I \frac{\mathrm{d}^{2} V(t)}{\mathrm{d} t^{2}} .
$$

At a normal respiratory rate, the inertial pressure $P_{\text {in }}$ can be neglected when compared to the elastic and resistive pressures; thus we consider that

$$
P_{\text {tot }}(t) \approx P_{\mathrm{el}}(t)+P_{\text {res }}(t)=E V(t)+R \frac{\mathrm{d} V(t)}{\mathrm{d} t} .
$$


For a patient breathing spontaneously, the total pressure $P_{\text {tot }}$ applied to the respiratory system results from the (negative) muscle pressure $P_{\text {mus }}$ and from the mouth pressure $P_{\mathrm{m}}$, as

$$
P_{\text {tot }}(t)=P_{\mathrm{m}}(t)-P_{\text {mus }}(t)=E V(t)+R \frac{\mathrm{d} V(t)}{\mathrm{d} t} .
$$

This equation is the dual of the equation of motion

$$
P_{\mathrm{mus}}(t)-P_{\mathrm{m}}(t)=E V^{\prime}(t)+R \frac{\mathrm{d} V^{\prime}(t)}{\mathrm{d} t},
$$

proposed by Mead \& Agostini [20], where $V^{\prime}$ is the lung volume related to the equilibrium volume and $\frac{\mathrm{d} V^{\prime}}{\mathrm{d} t}$ the airflow. A mechanical model corresponding to Eq. (7) was proposed by Mecklenburgh \& Mapleson [21] (Figure 3).

\section{A fitted quadratic model for $P_{\text {mus }}$}

The action of respiratory muscles is equivalent to a (negative) pressure applied to the chest wall. It has been shown that when compliance $C$ and resistance $R$ of a given subject are known, it is possible to reconstruct the times series of $P_{\text {mus }}$ from continuous measurements of the airflow $Q_{v}$ and from the mouth pressure $P_{\mathrm{m}}$ [22]. In this latter work, these measures were performed in 12 healthy subjects i) spontaneously breathing and ii) under ventilatory assistance. According to these results, the pressure $P_{\text {mus }}$ resulting from the respiratory muscles takes the form of a so-called relaxation oscillation. A breathing cycle

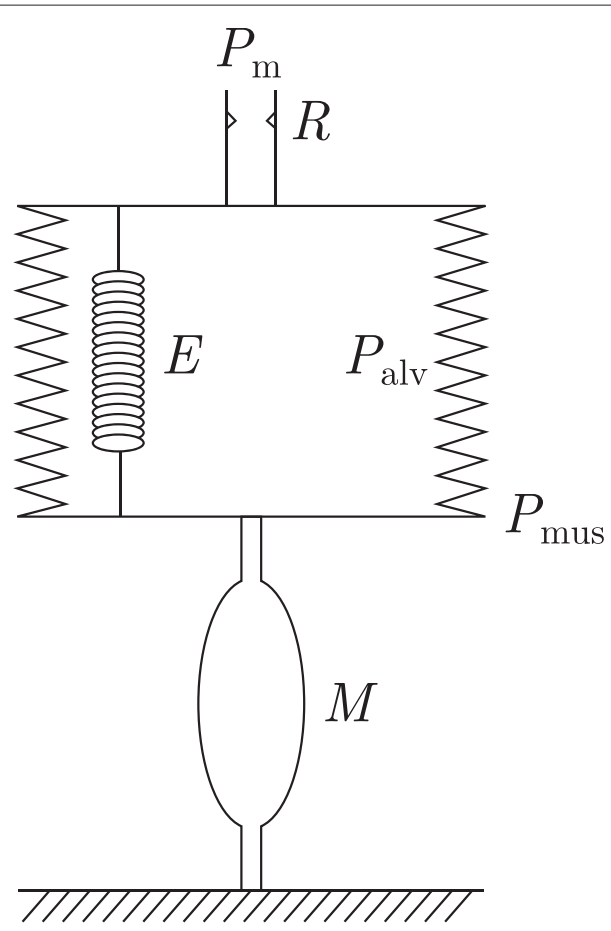

Figure 3 Mechanical analogy of the respiratory system. This mechanical model is equivalent to the ventilatory mechanics when inertance is neglected. The alveolar compartment is separated from the mouth by a resistance $R$. $P_{\mathrm{alv}}$ represents the pressure in the alveoli and $P_{\mathrm{m}}$ the pressure at the mouth. The respiratory muscles (both inspiratory and expiratory) are combined into a single muscle component $M$ which produces a negative pressure $P_{\text {mus. }} . E=\frac{1}{C}$ is the elastance (inverse of compliance $C$ ) of the respiratory system (redrawn from [21]) 


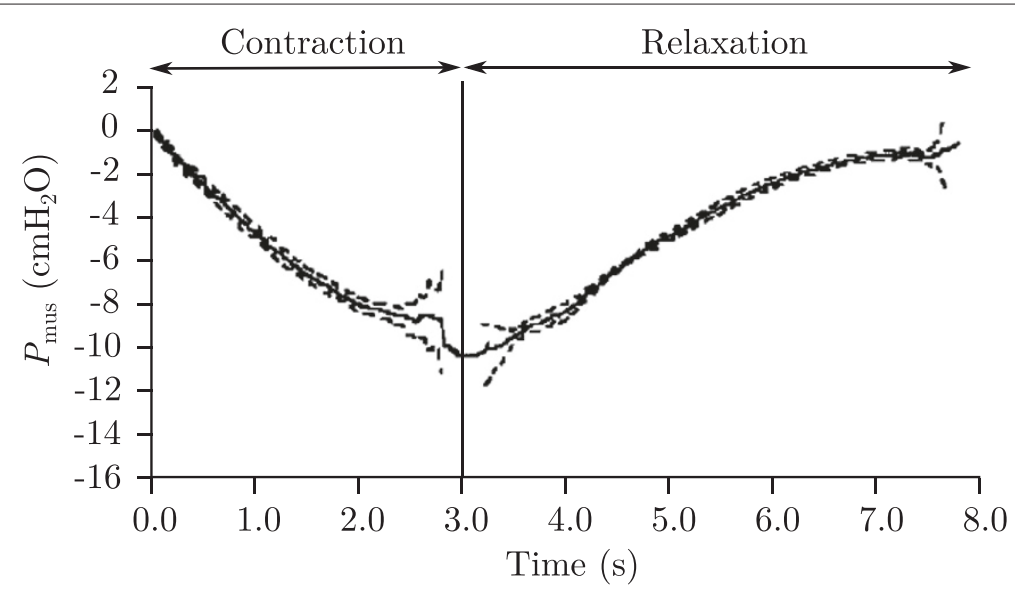

Figure 4 Measured pressure developed by respiratory muscles. Measured $P_{\text {mus }}$ (solid line) averaged over 12 subjects and $95 \%$ confidence limits (dotted lines) for the contraction and relaxation phases of a ventilatory cycle (adapted from [22]).

is thus split into two phases, inspiration and expiration, corresponding to contraction and relaxation of the respiratory muscles, respectively (Figure 4).

By fitting quadratic polynomials on the mean measured $P_{\text {mus }}$, Mecklenburg \& Mapleson described the relaxation oscillation of $P_{\text {mus }}$ by four quadratic polynomials in time according to

$$
P_{\text {mus }}(t)=\mid \begin{array}{ll}
-0.8445 t+0.12848 t^{2} & 0<t \leq 1.71 \mathrm{~s} \\
4.4408-6.0281 t+1.6975 t^{2} & 1.71 \leq t \leq 1.97 \mathrm{~s} \\
-2.5980+1.1317 t-0.1232 t^{2} & 1.97 \leq t \leq 4.59 \mathrm{~s} \\
0 & 4.59 \leq t \leq 4.74 \mathrm{~s}
\end{array}
$$

where one could consider that ventilatory cycle is split into i) a main contraction, ii) a kind of end-inspiration pause, iii) a main relaxation and iv) an end-expiratory pause. The resulting $P_{\text {mus }}$ time series (corresponding to a breathing cycle with a duration of $4.74 \mathrm{~s}$ ) is shown in Figure 5 . The shape of the $P_{\text {mus }}$ time series is not significantly affected by a ventilatory assistance or a resistance loading, and only the duration of the contraction and relaxation phases is changed [23]. Such a model for $P_{\text {mus }}$ is therefore quite general but only works for a ventilatory frequency set at 12.7 cycles per minute (cpm). Unfortunately, the

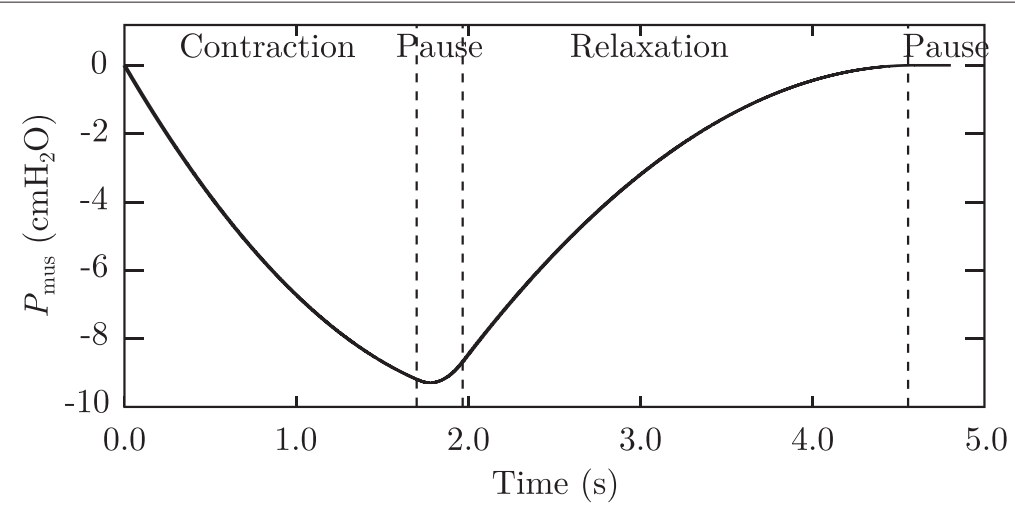

Figure $5 P_{\text {mus }}$ produced by the quadratic model. Time series of the muscle pressure $P_{\text {mus }}$ solution to the set of equations (8) corresponding to a mean breathing cycle. 
ventilatory frequency $f_{v}$ among patients is commonly observed in the range [10;30] cpm and, consequently, the $P_{\text {mus }}$ model (8) is not appropriate to simulate $P_{\text {mus }}$ time series for various breathing dynamics.

\section{Methods}

\section{A flexible dynamical model from an electrical analogy}

To be able to reproduce the inter-patient variability, it is thus desirable to construct a flexible model allowing to vary the amplitude as well as the duration of the contraction and relaxation phases. Since the time series shown in Figure 5 suggests charge and discharge of a conductance through a resistance, we developed a model dedicated to the muscle pressure and based on a $R C$-circuit as shown in Figure 6. We considered the inspiratory muscles as a powered system (through nerve impulses) producing a contraction followed by a relaxation as ventilatory muscles do during a breathing cycle. The contraction corresponds to the charge and the relaxation to the discharge of a capacitance $C_{m}$ through a resistance $R_{m}$. The capacitance $C_{m}$ characterizes the distension property of respiratory muscles and the resistance $R_{m}$ corresponds to the resistance produced via tendons and intramuscular structures such as myofibrils and connective tissue.

In this configuration, we consider that the input of the system is the voltage $U$ produced by the central nervous system and the output is the voltage $U_{\mathrm{rm}}$ across the capacitance $C_{\mathrm{m}}$ which corresponds to the voltage delivered by the respiratory muscles. We assumed that the capacitor is discharged at time $t=0$, that is $U_{\mathrm{rm}}(0)=0$. The characteristic equation of a capacitance is

$$
i_{C}=C_{m} \frac{\mathrm{d} U_{\mathrm{rm}}}{\mathrm{d} t}
$$

where $i_{C}$ is the current flowing through the resistance $R_{m}$ and $U_{\mathrm{rm}}$ the voltage across the capacitance $C_{m}$. By applying Kirchhoff's second rule to the circuit shown in Figure 6, we obtained the voltage $U_{\mathrm{rm}}$ corresponding to the muscle contraction as

$$
U=U_{R}+U_{\mathrm{rm}}
$$

where the voltage $U_{R}$ across the resistance is expressed as

$$
U_{R}=R_{m} i_{C}=R_{m} C_{m} \frac{\mathrm{d} U_{\mathrm{rm}}}{\mathrm{d} t} .
$$

During inspiration, $U=U_{\max }$ and a solution to the differential equation

$$
U=U_{\mathrm{rm}}+R_{m} C_{m} \frac{\mathrm{d} U_{\mathrm{rm}}}{\mathrm{d} t}
$$

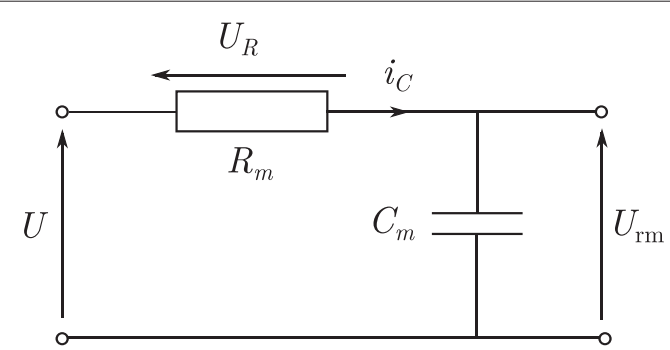

Figure $6 R C$-circuit equivalent to the respiratory muscles. Electrical circuit used to simulate the respiratory muscle activity. 
is

$$
U_{\mathrm{rm}}(t)=U_{\max }\left(1-e^{-\frac{t}{\tau}}\right)
$$

where $U_{\max }$ corresponds to the maximum pressure delivered by the muscle contraction and $\tau=R_{m} C_{m}$ is the time constant of the circuit. During expiration, it can reasonably be assumed that $U=0$ : the end of the nervous impulse induces the muscle relaxation. The solution to the resulting differential equation

$$
0=U_{C}+R_{m} C_{m} \frac{\mathrm{d} U_{\mathrm{rm}}}{\mathrm{d} t}
$$

is thus

$$
U_{\mathrm{rm}}(t)=U_{\max } e^{-\frac{t}{\tau}},
$$

where $U_{\mathrm{rm}}(0)=U_{\max }$ as expected at the end of the inspiration (and so at the beginning of the expiration). From the mechanical point of view, the positive muscular contraction induces a negative pressure $P_{\text {mus }}$ in the respiratory system. Thus, $P_{\text {mus }}=-U_{\mathrm{rm}}$.

When simulating an inspiratory effort, the charge corresponds to the inspiratory phase whose duration must be chosen, and the discharge is associated with the expiratory phase. The duration of the breathing cycle is directly related to the patient ventilatory frequency $f_{v}$ that we choose to vary from 10 to $30 \mathrm{cpm}$ (cycles per minute) in order to simulate "normal" ventilatory dynamics corresponding to stable health conditions and faster dynamics observed in acute situations or during physical efforts.

Parameter $U_{\max }$ appearing in solutions (13) and (15) corresponds to the amplitude of the pressure delivered by the respiratory muscles. Solutions (13) and (15) are negative, that is, they are consistent with Mecklenburg and co-workers as well as with the definitions used in the ASL 5000.

In an electronic circuit, the time constant $\tau$ is the same for the charge and the discharge. In the respiratory system, the contraction (inspiration) is active and the expiration (relaxation) is passive. As a consequence, there are two distinct time constants $\tau_{c}$ and $\tau_{r}$ (this is equivalent to consider that the elastance is slightly different between inspiration and expiration) as discussed below. An oscillation of the pressure $P_{\text {mus }}$ corresponding to a breathing cycle is made of the two solutions (13) and (15) but with two different time constants as exemplified in Figure 7 for a breathing cycle whose duration is $T_{\text {tot }}=4.29 \mathrm{~s}$ and the inspiration duration is $T_{\mathrm{I}}=1.29 \mathrm{~s}$. The global morphology of $P_{\text {mus }}$ is in a good agreement with the mean curve provided by measurements (compare Figure 7 to Figure 4). Comparing the first two quadratic polynomials used by Mecklenburg and coworkers for the contraction with the single exponential function (13) shows a transition between contraction and relaxation stiffer than those observed in measurements. Nevertheless, triggering mechanisms in home ventilators are not sensitive to such a departure and this approximation will have (if any) a marginal effect on the synchronization between the pressure cycle delivered by the machine and the breathing cycle supplied by the mechanical lung.

\section{Inspiratory and expiratory durations}

The transition between inspiration and expiration is assumed to correspond to the onset of the relaxation of the ventilatory muscles. Solution (13) retained for the contraction 


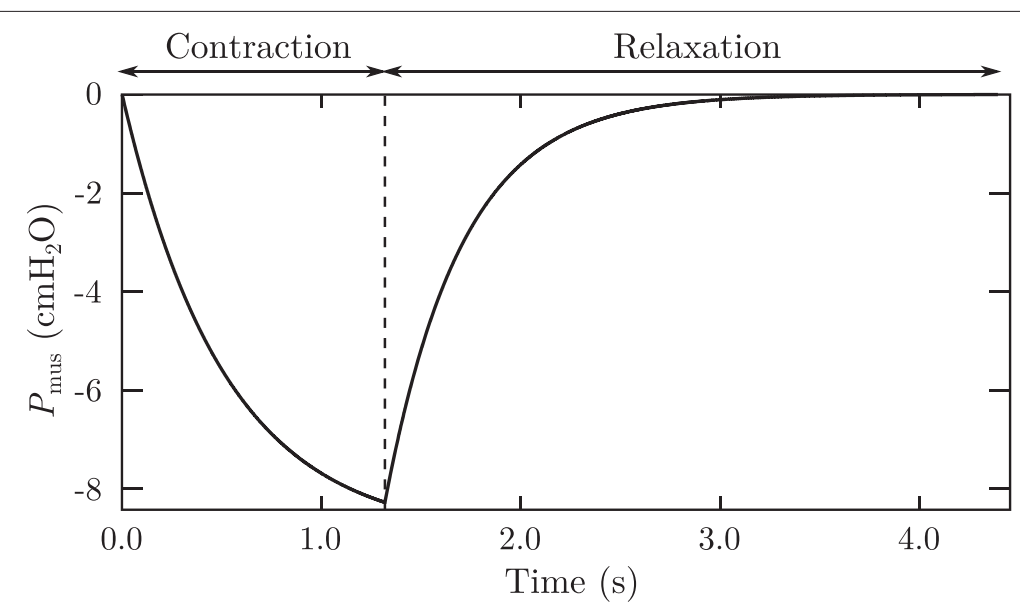

Figure 7 Simulated muscular pressure produced by the electric circuit. Solutions during inspiration (13) and expiration (15) were concatenated.

is valid between $t=0$ and $t=T_{\mathrm{I}}$, and solution (15) for relaxation is used between $t=T_{\mathrm{I}}$ and $t=T_{\text {tot }}$, where $T_{\text {tot }}$ is the duration of the breathing cycle. It has been shown that $\frac{T_{\mathrm{I}}}{T_{\mathrm{tot}}}$ is not constant when the ventilatory frequency $f_{v}\left(=\frac{1}{T_{\text {tot }}}\right)$ is varied [24]. When $f_{v}$ is increased, the expiratory time decreases faster than the inspiratory duration and, consequently, $\frac{T_{1}}{T_{\text {tot }}}$ increases. Physiologically, the inspiratory duration cannot be shorter than $0.5 \mathrm{~s}$ and longer than $1.5 \mathrm{~s}$. From the data provided in [24], $\frac{T_{\mathrm{I}}}{T_{\text {tot }}}$ is measured in healthy subjects within the range $[0.4 ; 0.6]$ when $f_{v}$ is varied within $[16 ; 51] \mathrm{cpm}$ using various levels of exercise. The ratio $\frac{T_{1}}{T_{\text {tot }}}$ for resting subjects is commonly between 0.3 and 0.4 [25].

From the data collected by Scheuermann and Kowalchuk, it appears that the ratio $\frac{T_{1}}{T_{\text {tot }}}$ is significantly correlated to the ventilatory frequency $(r=0.71, p<0.01)$. Nevertheless, the linear regression obtained from their data cannot be used since their measures were performed in subjects under exercise, contrary to patients who are commonly ventilated during their sleep. We thus retained a linear dependence roughly matching with $T_{\mathrm{I}}=1.5 \mathrm{~s}$ for $f_{v}=10 \mathrm{cpm}$ and $T_{\mathrm{I}}=1.0 \mathrm{~s}$ for $f_{v}=30 \mathrm{cpm}$, as observed in previous studies $[26,27]$. The ratio $\frac{T_{\mathrm{I}}}{T_{\mathrm{tot}}}$ thus depends on the ventilatory frequency according to

$$
\frac{T_{\mathrm{I}}}{T_{\text {tot }}}=0.0125 f_{v}+0.125 \text {. }
$$

The computed $\frac{T_{\mathrm{I}}}{T_{\text {tot }}}$ ratios and the inspiratory and expiratory durations are reported in Table 1. The obtained $\frac{T_{1}}{T_{\mathrm{tot}}}$ are between $0.25\left(f_{v}=10 \mathrm{cpm}\right)$ and $0.50\left(f_{v}=30 \mathrm{cpm}\right)$ and thus cover most of the range found in the published data.

\section{Amplitude and stiffness of the muscular pressure}

The respiratory muscle function is commonly assessed in clinical works by using the so-called mouth occlusion pressure $P_{0.1}$, measured $100 \mathrm{~ms}$ after the onset of inspiration during quiet breathing. $P_{0.1}$ is representative of the central unconscious control of breathing [28] and of the strength of the inspiratory demand. In healthy adults at rest, $P_{0.1}$ equals about $1 \mathrm{cmH}_{2} \mathrm{O}$ [29] with an unavoidable inter-subject variability $[30,31]$. The value for quiet breathing in healthy adults is $P_{0.1}=0.93 \pm 0.48 \mathrm{cmH}_{2} \mathrm{O}$ 
Table 1 Time parameters defining the phases of the breathing cycles: total duration $T_{\text {tot }}$ $\frac{T_{1}}{T_{\text {tot }}}$ ratio calculated from equation (16), and the associated inspiratory and expiratory times

\begin{tabular}{llllllll}
\hline $\boldsymbol{f}_{\mathbf{v}}(\mathbf{c p m})$ & $\mathbf{1 0}$ & $\mathbf{1 1}$ & $\mathbf{1 2}$ & $\mathbf{1 3}$ & $\mathbf{1 4}$ & $\mathbf{1 5}$ & $\mathbf{1 6}$ \\
\hline$T_{\text {tot }}(\mathrm{s})$ & 6.0 & 5.455 & 5.0 & 4.615 & 4.286 & 4.0 & 3.75 \\
$\frac{T_{1}}{T_{\text {tot }}}$ & 0.250 & 0.263 & 0.275 & 0.288 & 0.300 & 0.313 & 0.325 \\
$T_{\text {I }}(\mathrm{s})$ & 1.5 & 1.432 & 1.375 & 1.327 & 1.286 & 1.25 & 1.219 \\
$T_{\text {E }}(\mathrm{s})$ & 4.5 & 4.023 & 3.625 & 3.288 & 3.0 & 2.75 & 2.531 \\
\hline$f_{V}(\mathrm{cpm})$ & 17 & 18 & 19 & 20 & 21 & 22 & 23 \\
\hline$T_{\text {tot }}(\mathrm{s})$ & 3.529 & 3.333 & 3.158 & 3.0 & 2.857 & 2.727 & 2.609 \\
$\frac{T_{1}}{T_{\text {tot }}}$ & 0.338 & 0.350 & 0.363 & 0.375 & 0.388 & 0.400 & 0.413 \\
$T_{I}(\mathrm{~s})$ & 1.191 & 1.167 & 1.145 & 1.125 & 1.107 & 1.091 & 1.076 \\
$T_{\mathrm{E}}(\mathrm{s})$ & 2.338 & 2.166 & 2.013 & 1.875 & 1.75 & 1.636 & 1.533 \\
\hline$f_{V}(\mathrm{cpm})$ & 24 & 25 & 26 & 27 & 28 & 29 & 30 \\
\hline$T_{\text {tot }}(\mathrm{s})$ & 2.5 & 2.4 & 2.308 & 2.222 & 2.143 & 2.069 & 2.0 \\
$T_{T}$ & 0.425 & 0.438 & 0.450 & 0.463 & 0.475 & 0.488 & 0.500 \\
$T_{\text {tot }}(\mathrm{s})$ & 1.063 & 1.05 & 1.039 & 1.028 & 1.018 & 1.009 & 1.0 \\
$T_{\text {E }}(\mathrm{s})$ & 1.437 & 1.35 & 1.269 & 1.194 & 1.125 & 1.060 & 1.0 \\
\hline & & & & & & &
\end{tabular}

in [32] and, $0.75 \pm 0.32 \mathrm{cmH}_{2} \mathrm{O}$ in [33]. In this latter work, the occlusion pressure is found to be $2.83 \pm 1.27 \mathrm{cmH}_{2} \mathrm{O}$ in patients with chronic obstructive pulmonary diseases (COPD) and $2.41 \pm 1.01 \mathrm{cmH}_{2} \mathrm{O}$ in patients with restrictive lung disease. In a large cohort of 464 patients with chronic hypercapnic respiratory failure [34], the occlusion pressure is $P_{0.1}=4.69(3.57 ; 6.63) \mathrm{cmH}_{2} \mathrm{O}$ for patients with COPD, $P_{0.1}=3.67$ $(2.45 ; 5.51) \mathrm{cmH}_{2} \mathrm{O}$ for patients with an obesity hypoventilation syndrome (OHS) and, $P_{0.1}=2.55(1.43 ; 3.77) \mathrm{cmH}_{2} \mathrm{O}$ for patients with other various diseases. The main value is the median and values in parenthesis are quantile values. The occlusion pressure in patients with acute respiratory failure under mechanical ventilation assistance can be found within the range $[6 ; 10] \mathrm{cmH}_{2} \mathrm{O}[35-37]$ when the pressure support level is quite low.

According to these studies, most of clinical cases are considered when $P_{0.1}$ is varied from 0.5 to $10 \mathrm{cmH}_{2} \mathrm{O}$ (with an increment equal to $0.5 \mathrm{cmH}_{2} \mathrm{O}$ ). Combined with the ventilatory frequency $f_{v}$ which is varied between 10 and $30 \mathrm{cpm}$ with an increment equal to $1 \mathrm{cpm}$, the ventilatory dynamics is studied for

$$
\left(\frac{30-10}{1}+1\right) \times\left(\frac{10-0.5}{0.5}+1\right)=21 \times 20,
$$

that is, 420 different ventilatory dynamics, each pair $\left(f_{v}, P_{0.1}\right)$ corresponding to a given lung model (or a patient in a clinical equivalent). Our simulations then represent 420 lung models, thus taking into account the inter-patient variability.

\section{Results and discussion}

Parameters defining the inspiratory effort

Time constants $\tau$ appearing in equations (13) for describing the contraction and (15) for the relaxation of the respiratory muscles characterize the stiffness of the muscle dynamics. If this time constant is unique in a $R C$-circuit, this is not the case in the respiratory 
system because the muscular contraction is active and the relaxation is passive. Consequently, contraction is a shorter phenomenon than relaxation. These time constants depend on two parameters: the ventilatory frequency $f_{v}$ and the mouth occlusion pressure $P_{0.1}$. The first dependence is identical for both contraction and relaxation: we empirically choose to set the time constant $\tau$ at $\frac{10}{f_{v}}$. For contraction, such a relation leads to $\tau_{c}=1 \mathrm{~s}(0.33 \mathrm{~s})$ for $f_{v}=10 \mathrm{cpm}(30 \mathrm{cpm})$, thus corresponding to the inspiratory duration $T_{\mathrm{I}}=1.5 \mathrm{~s}(1 \mathrm{~s})$. The asymmetry between contraction and relaxation is introduced via the second dependence, that is the way the occlusion pressure $P_{0.1}$ affects such a constant. In both cases, increasing $P_{0.1}$ leads to an increase of the time constant. Since contraction is shorter than relaxation, the time constant $\tau_{c}$ for contraction must be more sensitive to $P_{0.1}$ than the time constant $\tau_{r}$ for relaxation. After trials and errors, we found that

$$
\tau_{c}=\frac{10}{f_{v}+4 \mathrm{P}_{0.1}}
$$

and

$$
\tau_{r}=\frac{10}{f_{v}+\frac{P_{0.1}}{2}} .
$$

induce $P_{\text {mus }}$ time series leading to airflow and pressure time series which look like those measured in patients (as we will show in the last section). In these two equations, $\tau$ is expressed in second, $f_{v}$ in cpm and $P_{0.1}$ in $\mathrm{cmH}_{2} \mathrm{O}$ (implicitly per $0.1 \mathrm{~s}$ ). Some values for these two time constants are reported in Table 2 for few values of $f_{v}$ and $P_{0.1}$. Typically, these time constants are in the range $[0.14 ; 0.98] \mathrm{s}$. They must be of the same order of magnitude as those associated with respiratory systems given by $\tau=R C$ as for any $R C$-circuit: the characteristic time constant is equal to $0.10 \mathrm{~s}$ for a restrictive patient $\left(R=5 \mathrm{cmH}_{2} \mathrm{O}^{-1} \mathrm{l}^{-1} \mathrm{~s}^{-1}\right.$ and $\left.C=20 \mathrm{ml} \cdot \mathrm{cmH}_{2} \mathrm{O}^{-1}\right)$ and to $1.25 \mathrm{~s}$ for an obstructive patient $\left(R=25 \mathrm{cmH}_{2} \mathrm{O}_{\mathrm{l}} \mathrm{l}^{-1} \cdot \mathrm{s}^{-1}\right.$ and $\left.C=50 \mathrm{ml} \cdot \mathrm{cmH}_{2} \mathrm{O}^{-1}\right)$. Time constants for the respiratory muscles are thus in a range corresponding to physiological values for the respiratory system.

The respiratory muscle pressure is thus explicitly governed by

$$
P_{\text {mus }}(t)=\mid \begin{array}{ll}
P_{\max }\left(1-e^{-\frac{f_{v}+4 P_{0.1}}{10} t}\right) & 0<t \leq T_{\mathrm{I}} \\
P_{\max }\left(e^{-\frac{f_{v}+\frac{P_{01}}{2}}{10} t}\right) & T_{\mathrm{I}}<t \leq T_{\text {tot }} .
\end{array}
$$

The ventilatory dynamics is clinically characterized by the ventilatory frequency $f_{v}$ (in $\mathrm{cpm})$ and the occlusion pressure $P_{0.1}\left(\mathrm{cmH}_{2} \mathrm{O}\right.$ per $\left.0.1 \mathrm{~s}\right)$. Since the mechanical lung is set using the maximum pressure $P_{\text {mus }}$ reached during the ventilatory cycle, it is thus useful

\begin{tabular}{|c|c|c|c|c|c|c|}
\hline \multirow[b]{2}{*}{$P_{0.1}\left(\mathrm{cmH}_{2} \mathrm{O}\right)$} & \multicolumn{2}{|c|}{$f_{v}=10 \mathrm{cpm}$} & \multicolumn{2}{|c|}{$f_{v}=20 \mathrm{cpm}$} & \multicolumn{2}{|c|}{$f_{v}=30 \mathrm{cpm}$} \\
\hline & $\tau_{c}$ & $\tau_{r}$ & $\tau_{c}$ & $\tau_{r}$ & $\tau_{c}$ & $\tau_{r}$ \\
\hline 0.5 & 0.83 & 0.98 & 0.45 & 0.49 & 0.31 & 0.33 \\
\hline 5 & 0.33 & 0.80 & 0.25 & 0.44 & 0.20 & 0.31 \\
\hline 10 & 0.20 & 0.67 & 0.17 & 0.40 & 0.14 & 0.29 \\
\hline
\end{tabular}

Table 2 Examples of the time constant $\tau_{c}$ for contraction and $\tau_{c}$ for relaxation for few values of the ventilatory frequency $f_{v}$ and of the occlusion pressure $P_{0.1}$

Time constants are in second. 
to express $P_{\max }$ in terms of $P_{0.1}$ and $f_{v}$. By definition,

$$
P_{0.1}=P_{\text {mus }}(0.1)=P_{\max }\left(1-e^{-\frac{f_{v}+4 P_{0.1}}{10} 0.1}\right)
$$

thus leading to

$$
P_{\max }=\frac{P_{0.1}}{1-e^{-\frac{0.1 \cdot\left(f_{v}+4 P_{0.1}\right)}{10}}},
$$

which can be used to define $P_{\max }$. Values of $P_{\max }$ are reported in Figure 8 for the 420 respiratory dynamics we are using for designing our "cohort of mechanical patients". Using Eq. (20), the $P_{\text {mus }}$ time series can thus be computed from the knowledge of $f_{v}$ and $P_{0.1}$, $P_{\max }$ and $T_{\mathrm{I}}$ being determined using Eqs. (22) and (16), respectively. These time series thus computed are then loaded in the mechanical lung software to drive the piston. Examples of the resulting $P_{\text {mus }}$ time series are shown in Figure 9 for four different ventilatory dynamics.

\section{Some simulations using the mechanical lung}

To validate our model, we chose to compare the airflow time series obtained from some simulations with the ASL 5000 to time series measured during a protocol which was conducted by Rabarimanantsoa-Jamous at the Rouen University Hospital during her Ph.D. thesis [38], in which written approval was obtained from the patients. In order to investigate how asynchrony events could affect the quality of noninvasive mechanical ventilation and sleep quality, airflow and airway pressure were measured during one night. The database consists of a cohort of 35 patients with respiratory diseases and daily assisted using a mechanical ventilator (VPAP III STA, ResMed, Australia). Some patients $(n=20)$

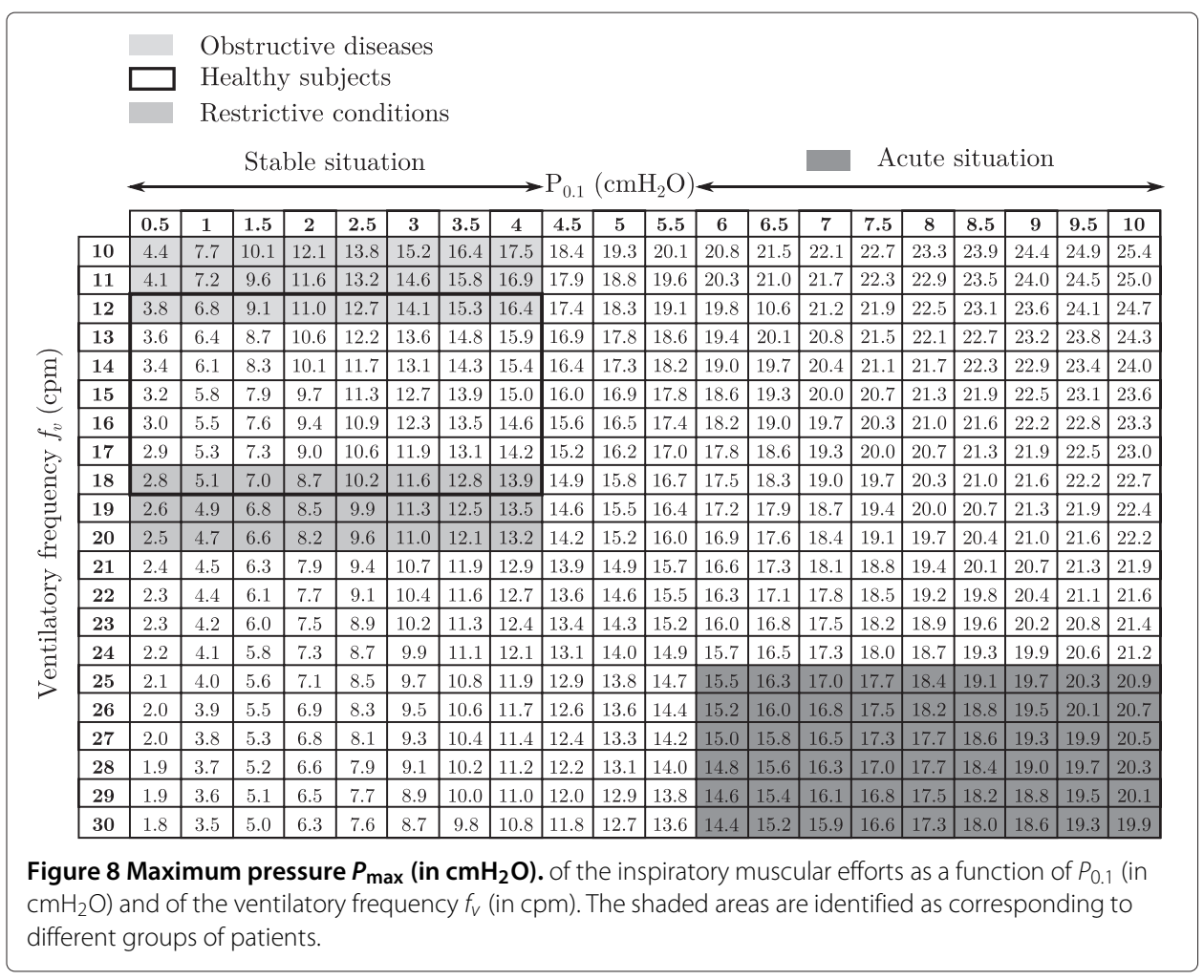




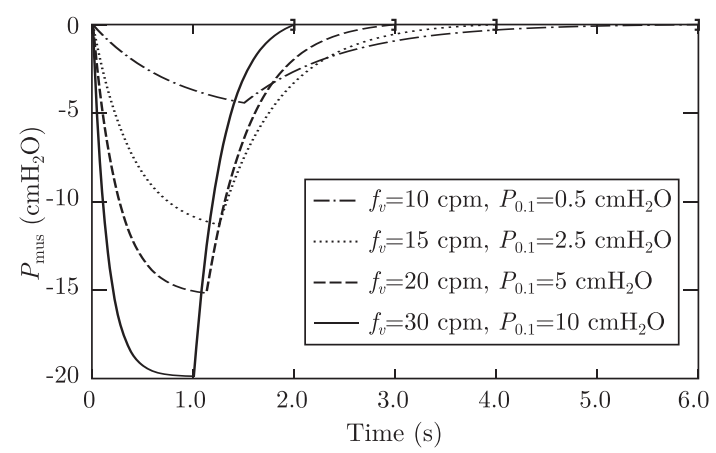

Figure 9 Simulated muscle pressures. Time series of the muscle pressure $P_{\text {mus }}$ simulated for four different ventilatory dynamics. The ratio $\frac{T_{1}}{T_{\text {tot }}}$ is determined according to Eq. (16).

were affected by obesity hypoventilation syndrome (OHS) and some other $(n=15)$ by chronic obstructive pulmonary disease (COPD), associated or not with sleep apnea. Mean body index (BMI) for these patients is $42 \pm 10.5$ and their mean age is $62 \pm 11.7$. We selected three airflow time series in this database, our aim being, first, to exemplify how different the dynamics underlying airflow time series can be different and, second, to show that we are able to reproduce these different dynamics with our model for the muscle pressure.

The first case corresponds to a 45 years old patient affected by OHS and sleep apnea; the ventilator is set with a high pressure $P_{h}=22 \mathrm{cmH}_{2} \mathrm{O}$, a low pressure $P_{l}=5 \mathrm{cmH}_{2} \mathrm{O}$ and the shortest pressure rise time. The measured airflow
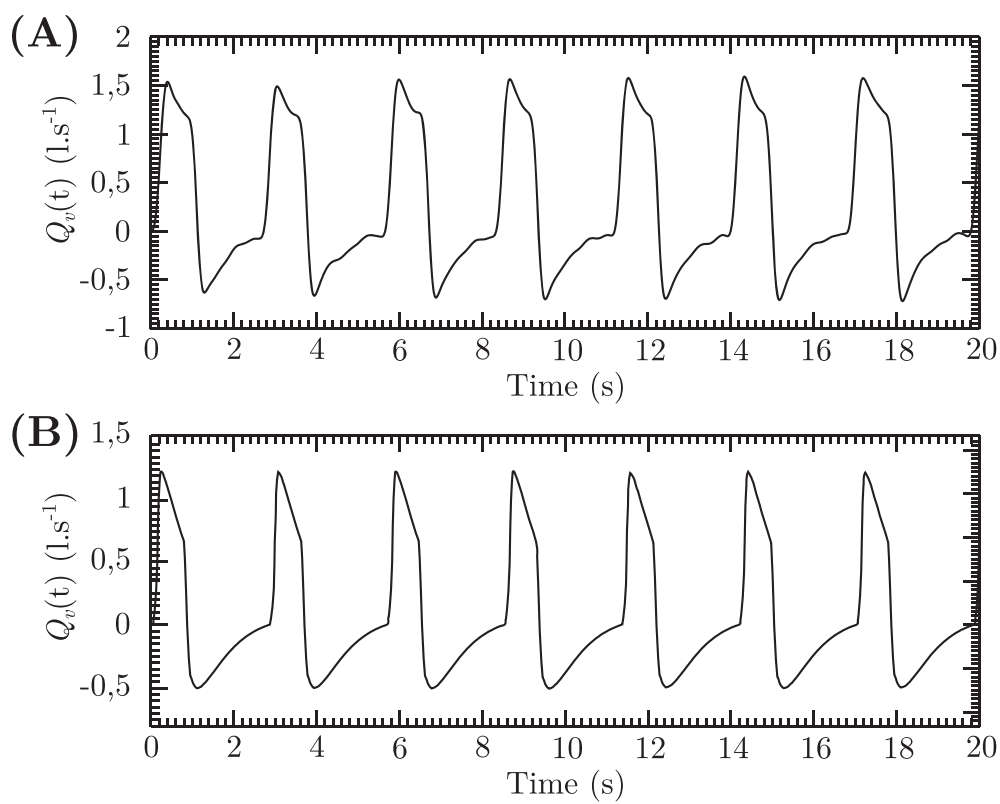

Figure 10 Patient airflow (A) and simulated curve (B). Case of a 45 years old male. (BMl= $35.4 \mathrm{~kg} \cdot \mathrm{m}^{-1}$ ) with an OHS and a sleep apnea syndrome, ventilated with a VPAP III ventilator (ResMed) in a pressure support mode. Pressure values: $P_{h}=22 \mathrm{cmH}_{2} \mathrm{O}$ and $P_{l}=5 \mathrm{cmH}_{2} \mathrm{O}$. These values were also used with the mechanical lung. We set $P_{0.1}=1 \mathrm{cmH}_{2} \mathrm{O}, R=5 \mathrm{cmH}_{2} \mathrm{O} / \mathrm{l} / \mathrm{s}$, and $\mathrm{C}=20 \mathrm{ml} / \mathrm{cmH}_{2} \mathrm{O}$, as commonly used for a restrictive patient (the actual values were not measured). 
(Figure 10A) presents a stiff rise up to nearly $1.51 . \mathrm{s}^{-1}$ which is followed by a fast decrease. Expiration is characterized by a fast return to a quasi-null airflow, with a plateau up to the end of the breathing cycle. The main characteristics of the airflow were reproduced in the time series (Figure 10B) simulated with a restrictive lung model (patient with OHS are considered as being restrictive). The ventilatory frequency was set at the measured value $(14.3 \mathrm{cpm})$. The ventilator was a VPAP III as used in the protocol with patients, and pressure levels were set as for this 45 years old male. We just adjusted the occlusion pressure (which was not measured in the the protocol) to optimize the airflow time series: we used $P_{0.1}=1$ $\mathrm{cmH}_{2} \mathrm{O}$.

The second case is a 74 years old woman also affected by OHS and sleep apnea; the ventilator pressure levels were $P_{h}=23 \mathrm{cmH}_{2} \mathrm{O}$ and $P_{l}=9 \mathrm{cmH}_{2} \mathrm{O}$. A long pressure rise time was used. The corresponding airflow time series (Figure 11A) presents a stiff rise, then a plateau which results from the long pressure rise time, and finally a fast decrease of the airflow up to a minimum negative value, followed by a slow return to a null airflow. Most of the characteristics of the measured airflow were reproduced with our restrictive lung model driven with a ventilatory frequency $f_{v}$ equal to the measured value $(17 \mathrm{cpm})$. The VPAP III ventilator was set as for this patient. The most corresponding airflow was obtained with the occlusion pressure $P_{0.1}=3 \mathrm{cmH}_{2} \mathrm{O}$ : this value greater than the one used for the first case can be justified by the BMI of the patient which is roughly twice the BMI of the first patient. The small plateau at nearly null airflow at the end of expiration was observed for the longest breathing cycles. Reducing the ventilatory frequency would have led to such a plateau with our simulation.
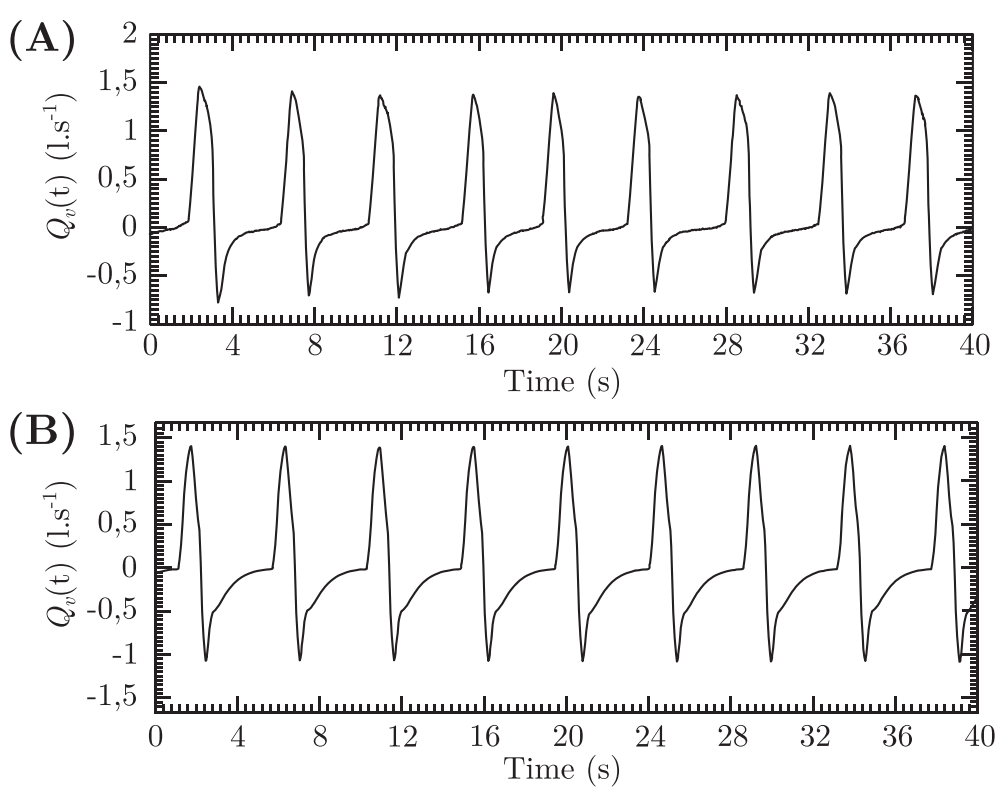

Figure 11 Patient airflow (A) and simulated curve (B). Case of a 74 years old female. (BMl $=66.5 \mathrm{~kg} \cdot \mathrm{m}^{-1}$ ) with an OHS and a sleep apnea syndrome, 0 ventilated with a VPAP III ventilator (ResMed) in a pressure support mode. Pressure values: $P_{h}=23 \mathrm{cmH}_{2} \mathrm{O}$ and $P_{l}=9 \mathrm{cmH}_{2} \mathrm{O}$. These values were also used with the mechanical lung. We set $P_{0.1}=3 \mathrm{cmH}_{2} \mathrm{O}$. $R$ and $C$ values were those used for the first case shown in Figure 10. 

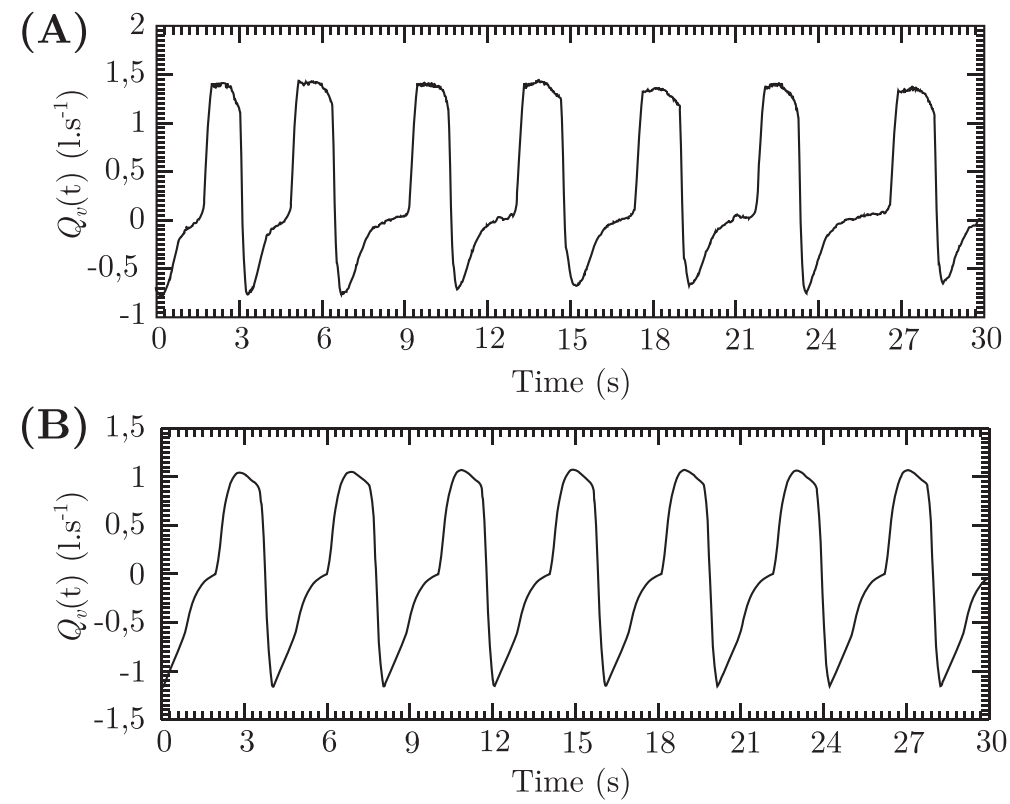

Figure 12 Patient airflow (A) and simulated curve (B). Case of a 62 years old male. $\left(B M l=50.2 \mathrm{~kg} \cdot \mathrm{m}^{-1}\right)$ with a COPD, ventilated with a VPAP III ventilator (ResMed) in a pressure support mode. Pressure values: $P_{h}=30 \mathrm{cmH}_{2} \mathrm{O}$ and $P_{l}=6 \mathrm{cmH}_{2} \mathrm{O}$. These values were also used with the mechanical lung. We set $P_{0.1}=4$, $R=25 \mathrm{cmH}_{2} \mathrm{O} / \mathrm{l} / \mathrm{s}$, and $\mathrm{C}=50 \mathrm{ml} / \mathrm{cmH}_{2} \mathrm{O}$, as commonly used for an obstructive patient (the actual values were not measured).

The third case is a 62 years old male affected by COPD ; the ventilator was set with pressure levels $P_{h}=30 \mathrm{cmH}_{2} \mathrm{O}$ and $P_{l}=6 \mathrm{cmH}_{2} \mathrm{O}$. The shortest pressure rise time was chosen. The associated airflow (Figure 12A) presents a stiff rise: once the maximum airflow is reached, there is a first slow decrease followed by an abrupt decrease of the airflow up to the minimum negative airflow. The second part of expiration is characterized by a rather slow increase of the airflow up to the nearly null value. The airflow time series simulated with an obstructive lung model (as required for a patient with a COPD) well reproduces the main features observed in the measured time series. The ventilatory frequency was set to the measured value $\left(f_{v}=23.1 \mathrm{cpm}\right)$. The best time series was obtained with $P_{0.1}=4 \mathrm{cmH}_{2} \mathrm{O}$.

For the three simulated time series, the amplitude of the expiratory airflow is always less than the expiratory airflow measured with patients. This is due to the fact that the airflow in ventilatory circuit with true patients was measured after the mask which contains intentional leaks to send the carbon dioxide out of the ventilatory circuit, thus avoiding carbon dioxide rebreathing. Contrary to this, the airflow in ventilatory circuit with the mechanical lung is measured within the piston chamber (the artificial lung), before any intentional leak. The presence of intentional leak has also an effect on the inspiratory airflow: the measured airflow with patient is overestimated because it takes into account the part flowing through the intentional leak and, consequently, not provided to the patient.

The transitions between inspiration and expiration in our simulations are stiffer than in the measured airflow. This could be also an effect induced by the location of the airflow sensor which differs in the two circuits. Such a stiffness is perhaps also 
induced by the fact that in our model the parameters used to simulate the pathophysiological conditions (the airway resistance $R$ and the thoracopulmonary compliance $C$ ) are kept constant during the simulations whereas they could change during inspiration and expiration [39]. As exemplified with the simulated time series shown in Figures 10, 11 and 12, such approximation did not prevent us to obtain airflow time series with characteristics close to those measured in ventilatory circuit with patient. We have therefore now a realistic mechanical lung model to assess performances of ventilators.

\section{Conclusion}

In this paper we designed a realistic respiratory muscle pressure to drive a mechanical lung such as the ASL 5000. In order to do that, we started from the scarce data available in the literature to define the main properties of the dynamics underlying the pressure driven by the respiratory muscles. Using an electrical analogy, we used two exponential functions, one for inspiration and one for expiration. In order to have a muscular dynamics only depending on the ventilatory frequency and the mouth occlusion pressure - two clinical parameters commonly measured - we introduced a linear dependency between the ratio of the inspiratory duration to the breathing cycle duration and the ventilatory frequency as suggested by clinical evidences. The resulting model was validated by comparing simulated airflow time series measured in the mechanical lung driven by our model with those measured in ventilatory circuits with patients. By varying the ventilatory frequency and the mouth occlusion pressure we are now able to reproduce the inter-patient variability and, consequently, to investigate performances of ventilators on a "cohort" of realistic lung models.

\section{Consent}

Written informed consent was obtained from the patients for the publication of this report and any accompanying images.

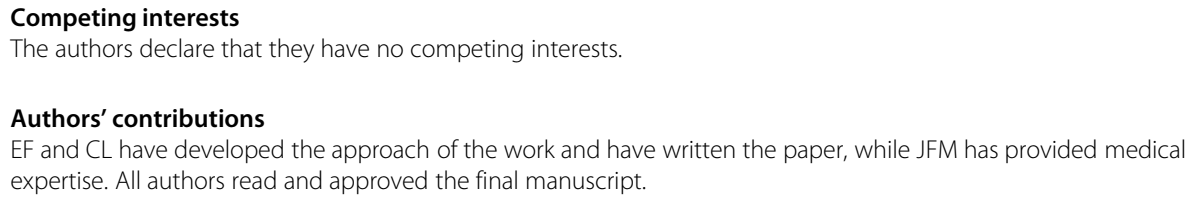


3. Thille AW, Rodriguez P, Cabell B, Lellouche F, Brochard L: Patient-ventilator asynchrony during assisted mechanical ventilation. Intensive Care Med 2006, 32:1515-1522.

4. Naeck R, Bounoiare D, Freitas US, Rabarimanantsoa H, Portmann A, Portier F, Cuvelier A, Muir J-F, Letellier C: Dynamics underlying patient-ventilator interactions during nocturnal noninvasive ventilation. Int J Bifurcation Chaos 2012, 22(2):1250030.

5. Cuvelier A, Achour L, Rabarimanantsoa H, Letellier C, Muir J-F, Fauroux B: A noninvasive method to identify ineffective triggering in patients with noninvasive pressure support ventilation. Respiration 2010, 80:198-206.

6. Chao DC, Scheinhorn DJ, Stearn-Hassenpflug M: Patient-ventilator trigger asynchrony in prolonged mechanical ventilation. Chest 1997, 112:1592-1599.

7. Leung $P$, Jubran $A$, Tobin MJ: Comparison of assisted ventilator modes on triggering, patient effort, and dyspnea. Am J Respir Crit Care Med 1997, 155:1940-1948.

8. Nava S, Bruschi C, Rubini F, Palo A, lotti G, Braschi A: Respiratory response and inspiratory effort during pressure support ventilation in COPD patients. Intensive Care Med 1995, 21:871-879.

9. Tassaux D, Gainnier M, Battisti A, Jolliet P: Impact of expiratory trigger setting on delayed cycling and inspiratory muscle workload. Am J Respir Crit Care Med 2005, 15:1283-1289.

10. Chopin C, Chambrin M: Essai de classification des modes actuels de ventilation mécanique en pression positive. Réanimation Urgence 1998, 7:87-99.

11. Olivieri C, Costa R, Conti G, Navalesi P: Bench studies evaluating devices for non-invasive ventilation: critical analysis and future perspectives. Intensive Care Med 2012, 38:160-167.

12. Stell IM, Paul G, Lee KC, Ponte J, Moxham J: Non-invasive ventilator triggering in chronic obstructive pulmonary disease. A test lung comparison. Am J Respir Crit Care Med 2001, 164:2092-2097.

13. Costa R, Navalesi P, Spinazzola G, Rossi M, Cavaliere F, Antonelli M, Proietti R, Conti G: Comparative evaluation of different helmets on patient-ventilator interaction during non-invasive ventilation. Intensive Care Med 2008 34:1102-1108.

14. Ferreira JC, Chipman DW, Kacmarek RM: Trigger performance of mid-level ICU mechanical ventilators during assisted ventilation: a bench study. Intensive Care Med 2008, 34:1669-1675.

15. Borel JC, Sabil A, Janssens JP, Couteau M, Boulon L, Lévy P, Pépin JL: Intentional leaks in industrial masks have a significant impact on efficacy of bilevel non-invasive ventilation: a bench test study. Chest 2009, 135:669-677.

16. Ferreira JC, Chipman DW, Hill NS, Kacmarek RM: Bilevel vs ICU ventilators providing non-invasive ventilation: effect of system leaks: a COPD lung model comparison. Chest 2009, 136:448-456.

17. Costa R, Navalesi P, Spinazzola G, Ferrone G, Pellegrini A, Cavaliere F, Proietti R, Antonelli M, Conti G: Influence of ventilator settings on patient-ventilator synchrony during pressure support ventilation with different interfaces. Intensive Care Med 2010, 36:1363-1370.

18. Chatburn RL: Which ventilators and modes can be used to deliver noninvasive ventilation? Respir Care 2009, 54(1):85-101.

19. Imbert A: Vitesses relatives des contractions musculaires volontaires et provoquées. L'année psychologique 1911, 18:47-54.

20. Mead J, Agostoni E: Dynamics of breathing. Handbook of Physiology. Washington, DC: American Physiological Society; 1964.

21. Mecklenburgh JS, Al-Obaidi TAA, Mapleson WW: A model lung with direct representation of respiratory muscle activity. Br J Anaesth 1992, 68:603-612.

22. Mecklenburgh JS, Mapleson WW: Ventilatory assistance and respiratory muscle activity. 1: Interaction in healthy volunteers. Br J Anaesth 1998, 80:422-433.

23. Mecklenburgh JS, Mapleson WW: Ventilatory assistance and respiratory muscle activity. 2: Simulation with an adaptive active ("aa" $i$ or "a-squared") model lung. Br J Anaesth 1998, 80:434-439,

24. Scheuermann BW, Kowalchuk JM: Breathing patterns during slow and fast ramp exercise in man. Exp Physiol 1999, 84(1):109-120.

25. Whipp BJ, Pardy RL: Breathing during exercise. Handbook of Physiology. Baltimore: Williams \& Wilkins for APS; 1986.

26. Rabarimanantsoa H, Achour L, Letellier C, Cuvelier A, Muir J-F: Recurrence plots and Shannon entropy for a dynamical analysis of asynchronisms in mechanical non-invasive ventilation. Chaos 2007, 17:013115.

27. Achour L, Letellier C, Cuvelier A, Vérin E, Muir J-F: Asynchrony and cyclic variability in pressure support noninvasive ventilation. Comput Biol Med 2007, 37:1308-1320

28. American Thoracic Society: European Respiratory Society: ATS/ERS Statement on respiratory muscle testing. Am J Respir Crit Care Med 2002, 166:518-624.

29. Burki NK, Mitchell LK, Chaudhary BA, Zechman FW: Measurement of mouth occlusion pressure as an index of respiratory centre output in man. Clin Sci Mol Med 1977, 53:117-123.

30. Whitelaw WA, Derenne JP: Airway occlusion pressure. J Appl Physiol 1993, 74:1475-1483.

31. Derenne JP, Couture J, Iscoe S, Whitelaw WA, Milic-Emili J: Occlusion pressure in man rebreathing $\mathrm{CO}_{2}$ under methoxyflurane anesthesia. J Appl Physiol 1976, 40:805-814.

32. Tobin MJ, Laghi F, Walsh JM: Monitoring of respiratory neuromuscular function., Principles and Practice of Mechanical Ventilation. New York: McGraw-Hill; 1994.

33. Scott GC, Burki NK: The relationship of resting ventilation to mouth occlusion pressure. An index of resting respiratory function. Chest 1990, 98(4):900-906.

34. Budweiser S, Jörres RA, Criée C-P, Langer V, Heinemann F, Hitzl AP, Schmidbauer K, Windisch W, Pfeifer M: Prognostic value of mouth occlusion pressure in patients with chronic ventilatory failure. Respir Med 2007, 101:2343-2351.

35. Herrera M, Blasco J, Venegas J, Barba R, Doblas A, Marquez E: Mouth occlusion pressure (P0.1) in acute respiratory failure. Intensive Care Med 1985, 11:134-139.

36. Berger KI, Sorkin IB, Norman RG, Goldring RM: Mechanism of relief of tachypnea during pressure support ventilation. Chest 1996, 109:1320-1327. 
37. Perrigault P-F-O, Pouzeratte YH, Jaber S, Capdevila XJ, Hayot M, Boccara G, Ramonatxo M, Colson P: Changes in occlusion pressure (P0.1) and breathing pattern during pressure support ventilation. Thorax 1999, 54:119-123.

38. Rabarimanantsoa-Jamous $\mathrm{H}$ : Qualité des interactions patient-ventilateur en ventilation non invasive nocturne. PhD Thesis. Université de Rouen; 2008.

39. Nikischin W, Gerhardt T, Everett R, Bancalari E: A new method to analyze lung compliance when pressure-volume relationship is nonlinear. Am J Respir Crit Care Med 1998, 158:1052-1060.

doi:10.1186/epjnbp//s40366-014-0007

Cite this article as: Fresnel et al:: Realistic human muscle pressure for driving a mechanical lung. EPJ Nonlinear Biomedical Physics 2014 2:7.

\section{Submit your manuscript to a SpringerOpen ${ }^{\odot}$ journal and benefit from:}

- Convenient online submission

- Rigorous peer review

- Immediate publication on acceptance

- Open access: articles freely available online

- High visibility within the field

- Retaining the copyright to your article

Submit your next manuscript at $>$ springeropen.com 